\title{
Juridiction conciliaire et juridiction pontificale au temps du concile de Bâle (1431-1449) : recours, procédures et suppliques
}

Doctorat d'histoire du Moyen Âge, sous le direction de Claude Gauvard, Université Paris I Panthéon-Sorbonne, soutenu le 6 décembre 2010.

\section{Émilie Rosenblieh}

\section{(2) OpenEdition}

\section{Journals}

Édition électronique

URL : http://journals.openedition.org/assr/24597

DOI : $10.4000 /$ assr.24597

ISSN : $1777-5825$

Éditeur

Éditions de l'EHESS

Édition imprimée

Date de publication : 30 décembre 2012

Pagination : 309-358

ISSN : 0335-5985

\section{Référence électronique}

Émilie Rosenblieh, « Juridiction conciliaire et juridiction pontificale au temps du concile de Bâle (1431-1449) : recours, procédures et suppliques », Archives de sciences sociales des religions [En ligne], 160 | octobre-décembre 2012, mis en ligne le 14 mars 2013, consulté le 19 avril 2019. URL : http:// journals.openedition.org/assr/24597

Ce document a été généré automatiquement le 19 avril 2019.

(c) Archives de sciences sociales des religions 


\section{Juridiction conciliaire et juridiction pontificale au temps du concile de Bâle (1431-1449) : recours, procédures et suppliques ${ }^{1}$}

Doctorat d'histoire du Moyen Âge, sous le direction de Claude Gauvard, Université Paris I Panthéon-Sorbonne, soutenu le 6 décembre 2010.

\section{Émilie Rosenblieh}

1 La juridiction se trouve au cœur des transformations du pouvoir que connut l'institution ecclésiastique dans la chrétienté latine à la fin du Moyen Âge. Saisir le concept de juridiction dans sa réalité médiévale suppose, en premier lieu, de se défaire de l'analyse tripartite des pouvoirs qui est héritée de la philosophie politique des Lumières. C'est une définition englobante de la juridiction qui prévalait au Moyen Âge. Cette notion incluait en effet les différentes facettes du gouvernement: le pouvoir de légiférer et d'administrer, mais également celui de rendre la justice et de concéder des grâces. Juristes et théologiens donnèrent une définition extensive de la juridiction qui permettait de justifier la hiérarchie ecclésiastique et, de ce fait, la primauté pontificale. Depuis la réforme grégorienne dans la seconde moitié $\mathrm{du} \mathrm{xI}^{\mathrm{e}}$ siècle, l'affirmation d'un droit proprement ecclésiastique se trouvait au fondement de l'autorité pontificale. À partir du $\mathrm{XIII}^{\mathrm{e}}$ siècle, les papes firent du procès un véritable mode de gouvernement. Aussi la juridiction se trouvait-elle liée à l'essor de la souveraineté pontificale, à travers le double processus de juridicisation et de judiciarisation que connut l'Église latine.

Dans les années 1430-1440, un conflit d'autorité survint au sommet de la hiérarchie ecclésiastique, entre le concile général et la papauté. Le concile qui se tint à Bâle de 1431 à 1449 contestait la légitimité du pape nouvellement élu et la primauté que celui-ci revendiquait sur l'assemblée. Les pères conciliaires prétendaient en effet représenter l'Église et participer au gouvernement de celle-ci. Dans ce contexte conflictuel, des auteurs, tels que le théologien Nicolas de Cues ou le canoniste Nicolas de Tudeschis dit le 
Panormitain, proposèrent une nouvelle définition de la juridiction, à la fois plus englobante et recentrée sur le pouvoir législatif.

3 À la faveur du conflit d'autorité survenu dans l'Église latine, le concile de Bâle contesta l'autocratie pontificale en ses fondements juridictionnels. Il prétendit exercer le pouvoir ecclésiastique suprême et gouverner la chrétienté latine en assemblée. Pour ce faire, les pères se dotèrent d'institutions et définirent des procédures qui étaient à la fois imitées de la Curie pontificale et adaptées à la nature collective de leur autorité ainsi qu'à leurs ambitions réformatrices. Qu'il s'agit de promulguer des décrets, d'administrer la justice ou la grâce, l'assemblée bâloise connut un processus d'institutionnalisation inédit. Cet essor s'accompagna d'une intense réflexion sur l'Église comme institution et comme société, et d'un profond renouveau de l'ecclésiologie. En témoigne la floraison des traités polémiques qui discutent la légitimité des pouvoirs juridictionnels exercés par le pape ou le concile. Notre travail étudie le concile de Bâle comme un laboratoire politique, qui fut propice aux expérimentations tant intellectuelles qu'institutionnelles dans l'exercice de la juridiction ecclésiastique suprême. En voici les principales conclusions.

Le concile de Bâle créa des institutions, afin de mieux s'opposer à l'autorité pontificale. Il s'agissait, tout d'abord, de protéger les pères et leurs proches des sanctions que le pape avait prononcées à leur encontre. L'essor institutionnel de l'assemblée se poursuivit bientôt en réponse aux sollicitations de fidèles originaires de toute la chrétienté latine, qu'il s'agît d'institutions ecclésiastiques, de clercs ou de laïcs. Au moyen de l'appel ou des suppliques, ceux-ci eurent recours à la justice et la grâce des pères. Pour traiter ces innombrables recours, le concile désigna des officiers, institua des tribunaux et définit des procédures délibératives inédites, destinées à garantir la prise de décision en assemblée. La précocité et l'ampleur de ces recours étonnent, et ce d'autant que le fait de juger des litiges courants et de concéder des grâces en assemblée ne relevait pas de la tradition institutionnelle de l'Église. Appels et suppliques seraient le signe de l'acculturation des clercs au phénomène conciliaire. Sans doute cette acculturation résulte-t-elle de la réunion périodique du concile général dans la première moitié $d u \mathrm{xv}^{\mathrm{e}}$ siècle, qu'il s'agit de mettre un terme au Grand Schisme d'Occident (1378-1417) ou de réformer l'Église. Le transfert de souveraineté que les pères tentèrent d'opérer de la papauté vers leur assemblée suscita l'adhésion d'une partie non négligeable du clergé voire, plus largement, de la communauté chrétienne.

5 Les registres de procès et de suppliques qui sont conservés à Bâle, Lausanne et Genève témoignent de la volonté des pères de se doter de véritables archives. Ces registres permettent de cerner les pratiques institutionnelles propres à l'assemblée bâloise. Dans les actes de la pratique, le concile apparaît comme tiraillé entre, d'une part, la volonté réformatrice de gouverner en assemblée et, d'autre part, la nécessité pratique de déléguer son pouvoir. Cette tension animait en particulier l'administration conciliaire de la grâce et de la justice. Pour examiner les requêtes qui leur étaient adressées, les pères élaborèrent une procédure d'examen complexe, qui faisait intervenir successivement les différentes commissions constitutives de l'assemblée, au risque d'en accaparer les débats. L'analyse de la justice conciliaire se fonde sur trois études de cas : un litige courant et une affaire épiscopale, ainsi que le procès éminemment politique que les pères intentèrent contre le pape Eugène IV. L'étude de ces procès montre à quel point l'assemblée limita la délégation de ses pouvoirs judiciaires, que ce fût dans la durée ou dans l'ampleur des missions confiées aux juges instructeurs. Le concile mettait en œuvre un processus délibératif d'une grande complexité, pour instaurer et contrôler les délégations. Aussi les 
aspirations réformatrices à une juridiction exercée en assemblée risquaient-elles de conduire la bureaucratie conciliaire au blocage.

Le conflit survenu entre les autorités pontificale et conciliaire se cristallisa sur la question de la hiérarchie des normes dans l'Église. Le concile entendait en effet réformer l'institution ecclésiastique par sa législation et imposer le respect de ses décrets au pape. Eugène IV (1431-1447) ne se sentait, pour sa part, pas tenu d'observer les décrets réformateurs qui limitaient sa souveraineté, en particulier sur la désignation des prélats, en matière judiciaire ou fiscale. Faute de pouvoir l'amener à respecter sa législation, le concile instruisit le procès du pape. L'accusation se concentra sur les crimes liés au gouvernement de l'Église, à l'exclusion de tout crime sexuel ou magique. Au cours de la procédure, le mépris pour l'autorité conciliaire fut progressivement défini comme constitutif de l'hérésie. Le 25 juin 1439, l'assemblée bâloise prononça la déposition d'Eugène IV reconnu hérétique, après quoi un nouveau pape fut élu, qui prit le nom de Félix V (1439-1449). Ce schisme ne manqua pas d'aviver la polémique ecclésiologique.

7 Dans de nombreux traités pour la plupart inédits, les partisans de l'autorité conciliaire défendirent leur conception de l'Église, à grand renfort de citations bibliques et juridiques. Ils donnèrent des textes cités une interprétation favorable à l'autorité conciliaire. Parmi les collections canoniques, ils se référèrent en particulier aux dispositions les plus anciennes, vestiges d'une Église sans pape, du moins antérieurs à l'affirmation de l'autorité pontificale. Leur argumentation fut ardemment combattue à la Curie par les défenseurs de la primauté pontificale. La polémique anticonciliaire exerça une influence profonde sur l'écriture de l'histoire officielle de l'Église, qui condamna la mémoire de l'assemblée bâloise. Les dissidences religieuses furent, au contraire, le terreau des premiers travaux consacrés aux sources et à l'histoire du concile de Bâle. Les érudits gallicans, en premier lieu desquels figure le bibliothécaire du roi de France Étienne Baluze (1630-1718), apportèrent une précieuse contribution à l'édition des décrets conciliaires comme à la collecte de manuscrits de l'assemblée bâloise. Les conciles de Vatican I (1869-1870) et de Vatican II (1962-1965) ont, certes, stimulé l'intérêt des historiens pour l'étude du phénomène conciliaire. Mais le conflit ouvert dans les années 1430-1440 a continué de peser sur l'écriture de l'histoire, biaisant ou limitant l'étude du laboratoire politique que fut le concile de Bâle.

8 Quelles qu'aient pu être les difficultés institutionnelles rencontrées par les pères et l'âpreté des tensions survenues entre la papauté et leur assemblée, les innovations tentées à Bâle marquèrent profondément l'institution ecclésiastique. Le pape ne parvint à rétablir son autorité sur la chrétienté latine divisée que par l'exercice patient de son pouvoir de grâce. Extrêmement lent, ce processus de pacification se poursuivit pendant plusieurs décennies après la dispersion des derniers pères, à Lausanne en 1449 , comme le montrent les sondages effectués dans les registres pontificaux. Certaines des expérimentations conceptuelles et institutionnelles de l'assemblée bâloise exercèrent leur influence sur les pratiques de l'Église ainsi que des États de la chrétienté latine. Les pères menèrent des réflexions et des procédures qui ébranlèrent l'autorité pontificale dans ses fondements juridictionnels, sans toutefois concevoir l'institution ecclésiastique hors du paradigme de la papauté. 


\section{NOTES}

1. À paraître: Gouverner l'Église en assemblée : l'expérience du concile de Bâle (1431- 1449), Leyde, Brepols, coll. « Ecclesia militans ».

\section{AUTEUR}

\section{ÉMILIE ROSENBLIEH}

emilie_rosenblieh@yahoo.fr 